\title{
COMPARAÇÃO DA SENSIBILIDADE DE TRÊS DIFERENTES TÉCNICAS COPROPARASITOLÓGICAS PARA DIAGNÓSTICO DE HELMINTOS EM CÃES
}

(Comparison of sensitivity of three different coproparasitological techniques for helminth diagnosis in dogs)

${ }^{1}$ Douglas Luís Vieira, ${ }^{2}$ Viviane Milczewski, ${ }^{1}$ Marcelo Beltrão Molento

${ }^{1}$ Universidade Federal do Paraná, Curitiba, Paraná, Brasil. ²Instituto Federal Catarinense, Santa Catarina, Brasil.

*Correspondência: douglasluisvieira@gmail.com

RESUMO: Os helmintos gastrintestinais de cães são uma das principais fontes de contaminação ambiental e agressão aos animais. O controle dessas parasitoses é importante tanto para a saúde animal como humana. Helmintos dos gêneros Ancylostoma e Toxocara estão envolvidos em casos de zoonoses por exemplo, causando respectivamente a larva migrans cutânea e visceral. Tendo em vista a importância desses agentes etiológicos, o presente estudo tem por objetivo calcular e avaliar a sensibilidade de três diferentes técnicas coproparasitológicas comumente utilizadas na rotina clínica e determinar qual técnica possui o diagnóstico mais sensível para helmintos de cães. DRYDEN et al., (2006) consideram não haver uma técnica padrão-ouro confiável para os estudos de comparação, e propõem a classificação das amostras em verdadeiramente positivas e negativas baseado em critérios envolvendo mais de uma técnica diagnóstica. Para tal, foram utilizadas 81 amostras de fezes de cães, entre eles adultos e filhotes acima de seis meses, provenientes do Centro de Bem-estar Animal do Município de São Francisco do Sul, SC. Todas as amostras passaram por processamento para três técnicas coproparasitológicas, sendo elas flutuação em solução saturada de $\mathrm{NaCl}$ (Técnica de Willis), centrífugo-flutuação em solução 33\% de sulfato de zinco (Técnica de Faust) e sedimentação em $\mathrm{H}_{2} \mathrm{O}$ (Técnica de Hoffmann). Para calcular a sensibilidade foi utilizada a equação definida pela Organização Pan-americana de Saúde (OPAS, 2020) [(A / $(A+C) \times 100]$. Onde A representa os casos verdadeiro-positivos (amostras positivas em pelo menos uma das técnicas realizadas) e $C$ representa os casos falso-negativos (amostras negativas para a técnica avaliada, porém positiva em outra técnica). Das 81 amostras, 60 (74,1\%) foram verdadeiro-positivos para algum tipo de helminto de cão e 11 (13,6\%) amostras foram verdadeiro-negativos (negativos nas três técnicas realizadas). A técnica de flutuação foi a que apresentou a melhor sensibilidade com $98,4 \%$, seguida pela técnica de centrífugo-flutuação com sensibilidade de $78,6 \%$. A técnica de sedimentação foi a que teve a menor sensibilidade com apenas $42,9 \%$. Com base nos resultados encontrados, podemos afirmar que a técnica de flutuação é a que tem melhor sensibilidade e pode ser a escolha para diagnóstico quando houver suspeita de helmintoses em cães.

Palavras-chave: técnica de flutuação; técnica de centrífugo-flutuação; técnica de sedimentação.

Agradecimentos: Os autores agradecem ao Centro de Bem-estar Animal do Município de São Francisco do Sul, SC.

\section{Referências}

DRYDEN, M.W.; PAYNE, P.A.; SMITH, V. Comparison of common fecal flotation technique for the recovery of parasite eggs and oocysts. Veterinary Therapeutics. v. 6. n. 1, p. 15-18. 2005.

ORGANIZAÇÃO PAN-AMERICANA DE SAÚDE. Abordagem diagnóstica. Biblioteca Virtual de Saúde: Atenção Primária em Saúde, 2020. Disponível em: < https://aps.bvs.br/apps/calculadoras/?page=1 >. Acesso em: 15 de Outubro de 2020. 